throughout the Empire become linked together in a common cause, reference may be made to banana research. Some twelve years ago the heavy losses resulting from the rapid spread of Panama disease-a soil-borne disease of great severity widely distributed throughout the tropics and affecting the Gros Michel banana, the principal variety of commerce-gave rise to a scheme requiring the services of a pathologist to study the malady under field conditions, of a plant breeder whose task was to produce commercial hybrids resistant to the disease, and of a physiologist to investigate the cold storage and ripening behaviour of resistant varieties or hybrids which might be used as commercial substitutes for the Gros Michel. These three sub-divisions of the research programme were centralized at the Imperial College, and among other things led to the construction of plant quarantine houses and of a Low Temperature Research Station. But only part of the story has been told. To search for resistant varieties which might serve as substitutes for the Gros Michel and to provide materials from which desirable hybrids might be obtained, collectors from the Royal Botanic Gardens at Kew were sent to the East, the original home of the banana. In this unusual quest, which still continues, forestry and agricultural officers in remote places have taken a not inconsiderable part. Further, in order that diseases which have attained to epidemic proportions in the Orient might not be introduced into the West Indies, it was necessary to prepare a special quarantine house at Kew and one in Trinidad to provide the necessary safeguards. Meanwhile, in Trinidad, with the passage of time, new and promising hybrids have been raised and their carrying qualities tested, and a vast amount of useful information has been obtained and published on the botany of this important genus, the behaviour of different varieties and hybrids in storage, the basic physiological pro- cesses involved, and on the host of diseases which are liable to cause losses in the field and wastage during transport and ripening. By such a combination of effort it is evident that not only are present needs being served, but also a sure foundation of knowledge is being laid down for the future.

The fascinating story of banana investigations is only one illustration of the many research projects now receiving attention at the College. Reference might equally have been made to work on such crops as cacao, citrus, sugar cane; to storage investigations on exotic fruits; to soil surveys and kindred earthy topics ; to economic probings into the workings of tropical industries and social systems ; and to the many and varied problems of entomology and mycology. Lastly, it may be noted, a special point is made of introducing students to these manifold activities; as a result they go forth, not only with some knowledge of the methods by which problems may be tackled, but also with the feeling that they have, to some extent, become personally identified with researches whose value will become increasingly evident with the passage of time.

In a free world the fruits of knowledge should be available to all. This ideal pervades the work of the Imperial College of Tropical Agriculture. The results of all investigations are published in appropriate journals, and scholarly contacts are maintained with research workers throughout the world. Visitors are made welcome and given the fullest access to such information as they may require. So is the good name of the College being spread abroad, not merely as a scientific adjunct to local aspects of tropical agriculture, but also as a centre of teaching and research where sincerity of scholarship, integrity of purpose, and a realistic vision for the future, must inevitably play a profoundly important part in aidinghumanity in a great practical need-to cultivate its tropical garden.

\title{
THE FOUNDATIONS OF EMPIRICAL KNOWLEDGE
}

\author{
By Prof. Herbert Dingle, \\ Imperial College of Science and Technology
}

$\mathrm{F}_{\mathrm{or}}^{\mathrm{on}}$ R more reasons than one it is important that those who are engaged in acquiring empirical knowledge should sometimes ask what it is precisely that they are doing, and what is the significance of their work. Much depends on the answer to this question, for in the long run it determines the direction which history takes. High explosive and incendiary bombs may destroy the material products of civilization, but if civilization survives it can produce others : a false idea is a bomb of the delayed action type which may destroy civilization itself. For this reason I have on more than one occasion protested against the false notion, coming unfortunately from authoritative sources within the world of science itself, that what we call empirical knowledge can be acquired with- 
out recourse to experience, and that future experience must conform to it.

This illusion is spreading, and philosophers are becoming its victims even more seriously than men of science. For whereas the scientific apostates substitute for experience the comparatively respectable goddess of reason, a vigorous and growing body of philosophers look to grammar as the source and essence of knowledge. Thus, R. Carnap, a leader among this group, maintains that what in science is usually called the ascertainment of an empirical fact by which a given hypothesis can be tested, is more properly described as the reduction, by formal conventional rules of syntax, of certain propositions, which constitute the hypothesis, to "observation-" or "protocol-sentences". These "observation-sentences", however, do not express the possible results of observation: the only criterion for determining their truth or falsity is the possibility of including them within the language used. But if the rules of the language make this impossible, we need not reject the hypothesis : "there always exists the possibility", Mr. A. J. Ayer quotes Carnap as saying, "of maintaining the hypothesis and renouncing acknowledgment of the protocol-sentences". Experience is eliminated altogether: knowledge consists of talking, and whatever you say is true if you do not contradict yourself.

In such a situation the appearance of a book on the foundations of empirical knowledge by a philosopher so acute and well informed in certain directions as Mr. Ayer*, is a matter of more than casual interest. It may be said at once that while Mr. Ayer has many affinities with the language school of philosophers, he does not share their determination to sidetrack observation: he believes that empirical knowledge originates only in experience, and that if you want to know whether the sentence "mercuric oxide is red" is true or not, you must look and see; it will not help you to study the rules of syntax. For this much must be forgiven him, and it may be that the service which he is thereby rendering to his day and generation is greater than he knows. Moreover, within the limits he sets for himself, he thinks with extreme clearness and expresses himself admirably. The book is a real pleasure to read. There is nothing here of the nebulous incomprehensibility which one often finds in philosophical works, and which one can only hope is a sign of profundity of thought. A sentence of Mr. Ayer's means one thing and one thing only, and you know what that thing is. Sentences are not repeated needlessly, and they succeed one another in perfect logical order. Apart from the rather annoying

* The Foundations of Empirical Knowledge. By Alfred J. Ayer. Pp. $\mathrm{x}+276$. (London: Macmillan and Co., Ltd., 1940.) 108. 6d. net. fact that the references in footnotes to other pages are usually wrong, there can be nothing but praise for Mr. Ayer's presentation of his case.

"My main purpose," Mr. Ayer writes, "has been to resolve the philosophical problems which are commonly brought under the heading of 'our knowledge of the external world'." The fundamental question which he considers is this : when (to use ordinary language) I "observe" a material thing, do I actually observe that thing, or something else (a "sense-datum") related thereto ? The latter would appear to be what I really observe because when I look at a shilling, for example, from a certain angle and in a certain light, I see a yellow ellipse, while from another angle I see a black line; but the shilling itself is a white circular disk. A generalization of such facts as these leads some philosophers to say that what we observe are always sense-data, although in special cases the description of the sense-data may be identical with that of the material thing. Mr. Ayer, however, maintains that the question is a purely verbal one. I can always say I observe a material thing if I give to the phrase "material thing" the requisite meaning. In my example I can say that I observed the shilling on each occasion and that it was a yellow ellipse at first and changed to a black line later. It would be a curious way of speaking, but it would not lead us into contradiction.

The question "Do I observe material things or sense-data?" therefore cannot be decided by an appeal to experience as could such a question as "Do I see sovereigns or Bank of England notes ?" Empirical facts can be described consistently whichever answer we give, and so the answer simply states what language we intend to use. If we appeal to facts, "it can be only to show that one form of expression is more convenient than the other". Mr. Ayer chooses the sense-datum language because, as he says, it is more convenient, and he proceeds to discuss how material objects can be "constructed" out of sense-data. Other questions also are dealt with, but this is the central one. What the thesis amounts to is this : the only condition a language has to satisfy is that its rules are free from self-contradiction, and between any two such languages the only ground for choice is convenience.

The first thought which all this arouses is that if our aim is merely to avoid contradiction, there is an admirable way of achieving it ; namely, by saying nothing at all. This is also extremely convenient. We conclude, then, that philosophers should henceforth remain for ever silent. But Mr. Ayer would doubtless object that of course we want to describe something-that something being, as he admits, experience. But if that is so, then 
surely there is another ground than convenience for choosing a language; we would prefer the one that enables us to say the most about experience. Here we see the grotesque inadequacy of $\mathrm{Mr}$. Ayer's discussion to his professed subject. He has set out to discuss "the foundations of empirical knowledge" - "the philosophical problems which are commonly brought under the heading of 'our knowledge of the external world' "-without reference at all to the facts that during the last three hundred years there has been a philosophical movement (now called science, thus enabling philosophers to ignore it) which has enlarged the scope and deepened the significance of our knowledge of the external world to such an extent that the knowledge thereof obtained otherwise is by comparison negligible ; and, second, that the condition which has made this possible is that men of science have progressively changed their language over and over again, invariably in order to be able to say more and more, and almost, if not quite, invariably from a more to a less convenient one. I will take two outstanding examples of this; but first let us see what kind of language science actually does use.

It is not the language of material things or that of sense-data as Mr. Ayer uses the term. It contains such words as "mass", "brightness", "shape", "motion", which represent groups of components of single sense-data. Jupiter is a material thing, but the mass of Jupiter is not a material thing. If Jupiter were to explode, the mass would continue undisturbed in its orbit at the centre of gravity of the fragments, while the material thing would be scattered in a million other places. The brightness of Jupiter is a function of something extending from the sun to the planet and then to the earth. The shape of Jupiter is a function of the number of times a metal bar at Paris would be contained in certain diameters if Jupiter were not moving with respect to it; and so on.

Each of these words can be ultimately expressed in terms of particular components of sense-data of Jupiter, but science is not in the least interested in putting the components together to make a sense-datum or in 'spelling out' Jupiter in terms of them. The mass of Jupiter is associated not with its brightness but with other masses, to give general laws of mechanics; and the brightness is associated not with the motion but with other luminosities, to give general laws of optics; and what science aspires to do ultimately is to subsume all such laws under a general correlation of all experience. The material thing, Jupiter, and the complete sense-datum of Jupiter, are alike without significance in this process, which, I repeat, has given us all but an infinitesimal fraction of our present knowledge of the external world. Yet Mr.
Ayer's discussion of the "philosophical problems" relating to such knowledge makes no reference whatever to it, but concentrates on the manner in which material objects can be described in the language of sense-data.

The first example of changes of scientific language which I will take is probably the best known in the whole history of science--the languages used to describe motion. In the Ptolemaic system, motion meant "change of position with respect to the earth". Copernicus changed this to "change of position with respect to the sun". This was a most inconvenient change-so inconvenient that the ordinary man has never made it; he still speaks of sunrise. Even the astronomer makes it very rarely. In the greater part of his work he talks of the celestial sphere, of right ascension and declination, and so on ; and the "Nautical Almanac", the indispensable handbook of applied astronomy, speaks practically without interruption in the Ptolemaic language (a fact which, it may be noted, is consistently overlooked by. those who hold scientific progress to have been directed by social needs). But the change enabled the astronomer to say more when he wanted to do so. He could, for example, describe the variations of a planet's brightness in terms of the new language but not in terms of the old, and Newton showed him how he could speak of such diverse things as the movements of the moon and the fall of an apple in the same new tongue. Therefore, because of its greater scope, and in spite of its greater inconvenience, that tongue became the official tongue of science.

Time went on, and astronomers wanted to say still more, so Einstein made another change. He recommended that motion should no longer mean change of position with respect to the sun, but the slope of a world-line in a four-dimensional continuum. In that language you can say all that. you said before, and more also. You can describe the motions of the planet Mercury, of light passing near the sun, and of the extra-galactic nebulæ. Is it a convenient language? Well, scarcely: it chokes you to speak it, but it allows you to 'say a mouthful'.

My second example shall be the scientific counterpart of one of Mr. Ayer's own-the only one for which I have space. In order to illustrate the equivalence (apart from convenience) of the languages of material things and sense-data, he instances the well-known fact "that a liquid will seem to have a different temperature according as the hand that is feeling it is itself hot or cold". In the language of sense-data, we have here two different sensedata associated with the same material object, and this contains no contradiction. If, however, we suppose that we are directly experiencing the same material thing with both hands, we appear to 
obtain the contradictory result that the water is both hot and cold. But "to obtain the contradiction it must also be assumed that the temperature of the water with which the vessel is filled is really the same throughout", and this assumption may be supported by the fact that "it is observed to yield a uniform reading on a thermometer". The contradiction may therefore be avoided by asserting that the water was really hot in one part and cold in the other, and hence that thermometer readings, made with the precautions usual in science, give untrustworthy indications of temperature. This would be the account of the matter in the material object language, and, according to Mr. Ayer, it is equivalent to the account in the sense-datum language in everything but convenience.

Again one cannot help asking: What about the scope of the languages? If thermometers cannot be trusted, then the only describable thermal phenomena are our direct sensations of heat and cold. Here is a pretty science of heat! Presumably the fact that the thermometer reads higher in boiling salt solution than in boiling water is "knowledge of the external world", but since our bodies would detect no difference we cannot connect this fact with the difference that we feel between a winter's and a summer's day. The latter is a difference of temperature, but we must invent a new and independent language to express differences of thermometer readings.

What has science done with phenomena of this kind? It has begun by defining the temperature of a body as the equilibrium reading of a thermometer-a mercury thermometer, say-immersed in the body. The difference in the sensations felt by the two hands must then be explained by supposing that they had different temperatures when immersed, and this is consistent with all other relevant facts available. The definition is not so convenient as that of direct feeling, but it enables us to connect together-to "speak about" -a wider range of phenomena. But the range is still unduly limited for the physicist. He cannot measure the temperature of a bunsen flame or liquid air with a mercury thermometer, so he changes his language to one in which temperature means the reading of a 'perfect gas' thermometer. A perfect gas never changes its state, however hot or cold it gets, so that in the new language we can talk about the temperature of anything which the universe may contain. As for convenience, there is, it is true, a slight disadvantage in the fact that neither a perfect gas nor the only equivalent substitute $-a$ reversible heat engine-can possibly exist, and we have to do the best we can with a real gas and make fairly elaborate corrections for its 'reality'. However, the physicist puts up with this, for he has only a pallid interest in convenience ; it is the scope of his language that stirs his blood.

One would think that he had now gone far enough. But no; he soon becomes dissatisfied with the perfect gas thermometer and gives the word "temperature" a new meaning: it next stands for "the average kinetic energy of the molecules of a body". This is quite a new departure. In terms of this language he says that the temperature of interstellar matter is something greater than $1000^{\circ} \mathrm{C}$, whereas he is quite confident that if a gas thermometer were placed in the matter it would read something near the absolute zero. Again the change is not made for convenience. If anyone thinks so, a page of Willard Gibbs will provide an infallible, though not a painless, corrective. The change is made solely because it enables us to speak of thermal and mechanical phenomena in the same language, and so enlarges our scope of expression.

So when Mr. Ayer tells us that a language which makes a thermometer reading an untrustworthy indication of temperature is equivalent in all but convenience to one in which a thermometer reading is trustworthy, the scientist must beg permission to dissent. It is true that, according to the latest definition, a thermometer no longer indicates temperature, but it is not untrustworthy, for we know why, and can predict when, it will fail. In interstellar space the matter is so rarefied that the thermometer receives impacts from the molecules very infrequently, and radiates away each increment of the acqutired energy before the next arrives. To know this is to increase our knowledge, while to reject the thermometer in favour of direct bodily sensations is drastically to restrict it.

The immense and awe-inspiring knowledge of the external world which we now possess, and which continues to grow at an almost incredible rate, is indeed a matter of the deepest concern. What does it all mean? Is it a discovery of unalterable fact, or a creation which our reason can transform as experience grows? How comes it that by taking thought in a particular way, unknown to the ancients, we can add unlimited cubits to our stature and determine the course of the world's history? What exactly are we doing, and what are the potentialities of the ideas to which we are led, when we set reason to operate on experience in the manner which has yielded the bulk of the empirical knowledge which is ours to-day ? The man of science, immersed in the process itself, rarely has the time or the aptitude to ponder these questions. He may realize their importance, but it is his chief function to produce the knowledge, not to assess it or discover its nature. For that we must look to the philosopher -to the man trained in the processes of accurate 
logic and versed in the history of human thought. On the philosopher, in the modern sense of the word, rests a great responsibility, perhaps the most urgent responsibility in the world to-day-that of laying bare the foundations of empirical knowledge so that we may use it with foresight instead of a blind understanding. And when we turn to what one of the most able and promising of the younger philosophers has to tell us on this allimportant question, we find that it is mainly a set of speculations on how to translate from one ineffective language into another. If $\mathrm{Mr}$. Ayer were a less significant figure we might in silence leave his book to psychologists, for whom the question it discusses, and perhaps the discussion itself, has some academic interest. It is because of the possibility that he might yet bring his great talents to bear on the problem which he thinks he has already considered that his book deserves serious attention.

\section{OB I T UAR IES}

\section{Prof. H. S. Hele-Shaw, F.R.S.}

$\mathrm{H}^{\mathrm{H}}$ ENRY SELBY HELE-SHAW, who died on January 30 at the age of eighty-six, combined in an unusual degree the academic and the inventive mind. Educated privately, he served an apprenticeship for four years as a mechanical engineer, after which he won a Senior Whitworth Scholarship and with it proceeded to University College, Bristol. On completing the course, he was appointed lecturer in mathematics and engineering at Bristol, and a few years after, in 1881, was made professor of engineering. Four years later he was appointed the first professor of engineering at University College, Liverpool. He held this post until his resignation in 1904, when he was appointed first professor of engineering in the Transvaal Technical Institute; after a year he was made principal of the Institute. Soon afterwards the Secretary of State for the Colonies appointed him organizer of technical education in the Transvaal.

On returning from South Africa in 1906, HeleShaw set up a consulting practice in Westminster and carried this on with great success until his death. He was president of the Institution of Mechanical Engineers in 1922, and president in 1915 of Section $\mathrm{G}$ (Engineering) of the British Association. He delivered the James Watt Anniversary Lecture in 1902 , the subject being "James Watt, Inventor". He was an LL.D. of St. Andrews, a D.Sc. of Bristol, and a D.Eng. of Liverpool.

While at Liverpool Hele-Shaw was largely responsible for collecting funds for the endowment of the chair of engineering and for the building of the Walker Engineering Laboratories. It was here, too, that he carried out his experimental work on streamline flow which established his reputation as a scientific investigator, and for which he was elected a fellow of the Royal Society in 1899.

It was during his early days at Liverpool that Hele-Shaw's inventive ability began to develop. He was much interested in the subject of friction and delivered four Cantor Lectures on the subject in 1886. It was about this time that he invented his well-known multiple-disk clutch. $\mathrm{He}$ also became very interested in road transport, and in 1897 organized the Liverpool trials of commercial vehicles for the Liverpool Automobile Club and Self-Propelled
Traffic Association. He became president of the Institution of Automobile Engineers in 1909.

After taking up consulting practice, Hele-Shaw developed several important inventions, among which his hydraulic variable-speed gear, the streamline filter, and the Victaulic pipe joint are especially worthy of mention. His most recent important work was on variable-pitch airscrews.

As an organizer of technical education Hele-Shaw did valuable work, especially in more recent years in connexion with the introduction of National Certificates. In 1920, when the Board of Education approached the Institution of Mechanical Engineers with a view to collaboration in a certificate scheme to take the place of the old Science and Art Certificates, Hele-Shaw was chairman of the Education Committee of the Council, and it was largely due to him that the scheme was adopted. He was the first chairman of the Joint Committee and held this post until 1937.

Until the end he was a remarkably vital character. As a lecturer he was breezy, humorous, and unconventional, and as such will be happily remembered by more than one generation of students.

\section{A. H. Gibson.}

\section{Sir Pendrill Varrier-Jones}

By the tragically sudden death on January 30 of Sir Pendrill Varrier-Jones in his fifty-eighth year the medical profession has lost a pioneer in the full tide of his activities. The only son of Dr. C. Morgan Jones of Glamorgan, he was educated at Epsom College and St. John's College, Cambridge, where he was a foundation scholar and prizeman, graduating in the first class of the Natural Sciences Tripos, Part 1. Proceeding to St. Bartholomew's Hospital he qualified there and became house physician. On the completion of his term of office he returned to Cambridge for pathological research under Sir German Sims Woodhead. At the outbreak of the War of 1914-18 the Cambridgeshire tuberculosis officer joined the R.A.M.C., and Varrier-Jones, who was graded as unfit for military service, was asked to undertake his work temporarily. He accepted with some reluctance, for hitherto his interests had been directed purely to laboratory research. 